\title{
Design and Development of a Frequency Inverter with the Intel 80C196MC Microcontroller
}

\author{
Pablo R. RIVERA ${ }^{1}$, Silvana P. GAMBOA ${ }^{1,2}$, and Paulo A. QUELAL ${ }^{1}$ \\ ${ }^{1}$ Departamento de Automatización y Control Indsutrial. Escuela Politécnica Nacional, \\ Isabel La Católica S/N Quito, Ecuador \\ Email : spgaben@yahoo.com²
}

\begin{abstract}
This paper reports on the development of a frequency inverter for speed control of an induction machine. The control is implemented on a $80 \mathrm{C196MC}$ microcontroller and the power system is implement using a three-phase bridge of IGBTs. Both, control and power circuit provide an output with variable voltage and frequency. The frequency and other parameters in the speed drive are manipulated from a humanmachine-interface HMI.
\end{abstract}

\section{INTRODUCTION}

The primary objective is to design a scalar control of a variable speed driver for a three-phase induction motor.

Its development is justified for necessity of efficient energy use. The use of special control techniques, Sinusoidal Pulse Wide Modulation (SPWM), guarantees an efficient work of the induction motor.

The prototype is development using an 80C196MC microcontroller. A scalar control algorithm guarantees a constant flow avoiding the increase of losses. In addition, torque is maintained in an wide speed range.

\section{INDUCTION MACHINE GENERALITIES}

\section{A. Frequency control}

The synchronous speed of an induction machine can vary by the adjusting the frequency of voltage applied to the motor terminals, as shown in equation (1).

$$
N_{S}=\frac{120 f}{P}
$$

Where: $f=$ voltage frequency

$\mathrm{P}=$ number of poles

Therefore, variable frequency will allow speed control of induction motor.

Frequency variation affects the maximum flux through the gap of the induction motor, as Equation (2) indicates. If flux is different to nominal flux, losses increase. Therefore, is necessary to maintain it constant.

$$
\begin{gathered}
E=4.44 \phi_{m} \cdot f \cdot K_{n} \\
V_{1} \approx K \cdot \phi_{m} \cdot f
\end{gathered}
$$

Constant flux is obtained when voltage and frequency change in a proportional way. Therefore, the applied voltage magnitude and frequency relationship should be kept constant.

$$
\frac{V_{1}}{f}=\text { CONSTANT }
$$

A change in frequency implies a change in the synchronous speed. Thus, the torque characteristic curve moves through the speed axis.

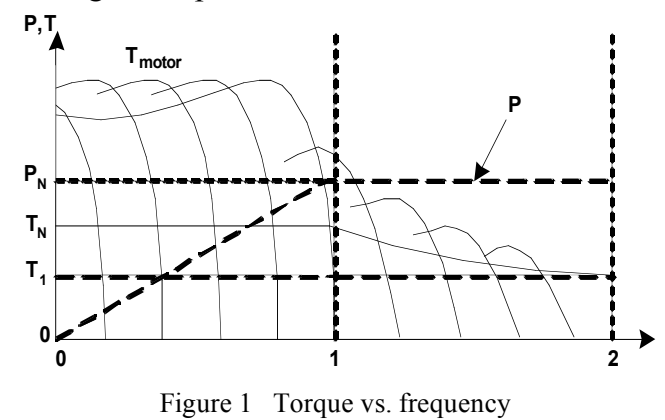

The voltage drop across the stator resistance increases considerably when the induction motor works with reduced frequency. Therefore, motor flux and maximum torque are reduced. In order to maintain the maximum torque it is necessary to compensate. Compensation is obtained by increasing the applied voltage and therefore the growth of the voltage with respect to the frequency is no longer linear (Figure 2) [6].

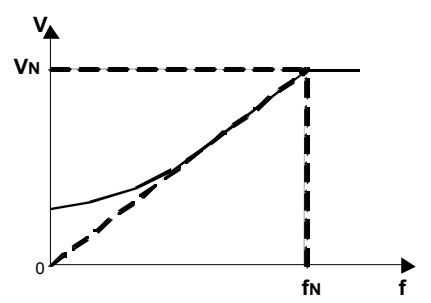

Figure 2 IxR Compensation

\section{B. Voltage-source inverter (VSI)}

An inverter is a DC - AC power converter. This converter obtains $\mathrm{AC}$ voltage from $\mathrm{DC}$ voltage. Its general configuration consists of the following components:

- Continuous voltage source.

- Continuous voltage coupler circuit, a capacitor for a VSI.

- Bridge of electronic-switches.

Figure (3) shows a typical VSI block diagram. 


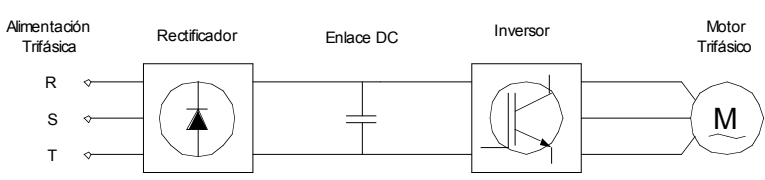

Figure 3 Voltage-source inverter

\section{Sinusoidal pulse-width modulation (SPWM)}

Pulse-width modulation is obtained by comparison of two different frequency waves a triangular and a sinusoidal (carrier and modulating). The sinusoidal voltage defines load current waveform and voltage frequency. The triangular voltage determines the switching frequency. The relation of the amplitude of both waves (carrier and modulating) is called modulation index MI, and determines the fundamental RMS output voltage.

The fundamental output RMS voltage varies in linear form with MI while it is less than one. When the MI is higher than one (overmodulation), the voltage does not increase proportionally with the MI (Figure 4) [1].

If the MI is constant through the frequency variation, the applied method is synchronous.

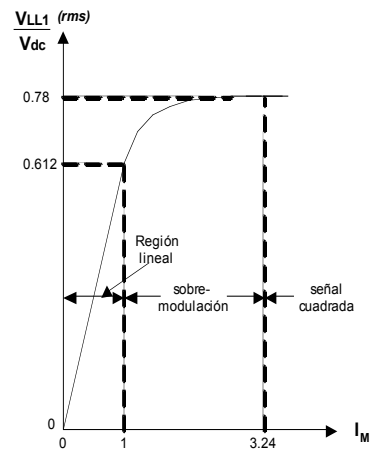

Figure 4 Voltage vs. $I_{M}$

The three-phase system is generated comparing three sinusoidal voltages that are $2 \pi / 3[\mathrm{rad}]$ out of phase with the same triangular voltage waveform. They provide the control signals for the upper side elements of the bridge, whereas the corresponding complement is for the lower elements. Thus, obtaining in each phase two level voltages as presented in Figure 5.

\section{Harmonic distortion in the SPWM technique}

SPWM with nonsinusoidal voltages, for that reason the harmonic content is high. In order to guarantee the harmonic elimination a high MI is necessary. On the other hand, the phase angle between the sinusoidal and the triangular waveforms determine the amplitude of certain harmonics. An acceptable phase angle occurs when the maximum peak of the sinusoidal is in the same place as the minimum peak of the triangular. For a three-phase system it is recommended that the MI is a multiple of three, with which the predominant harmonics will be eliminated in the line voltage.

Figure 6 shows harmonic content for different MI and $\varnothing$.

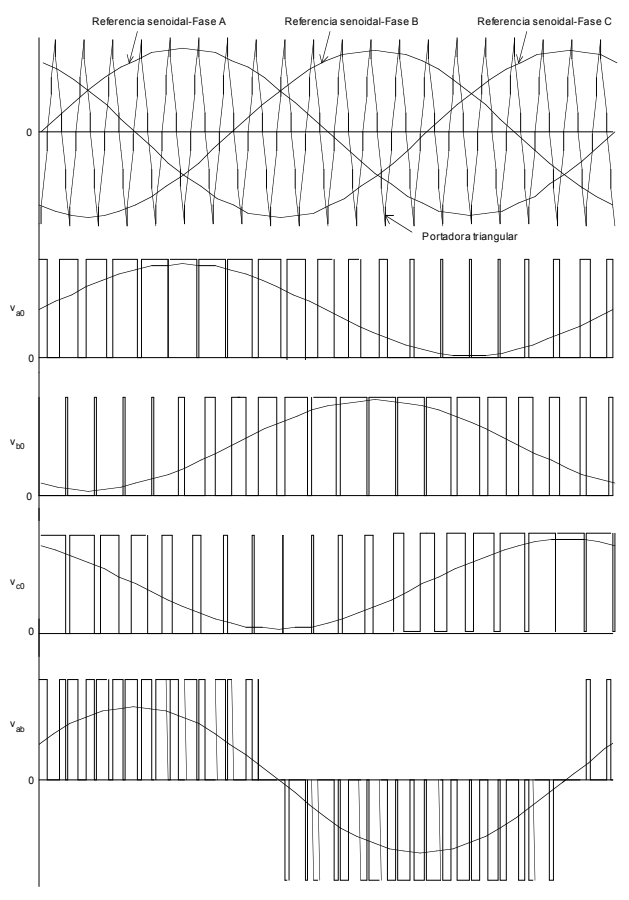

Figure 5 Three-phase inverter waveform voltage

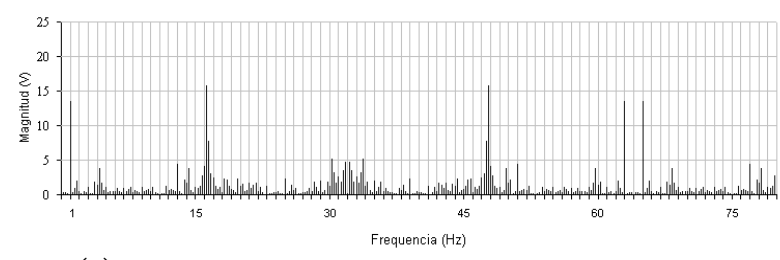

(a) $M_{f}=16.33 ; \quad I_{M}=0.7 ; \phi=$ indeterminado

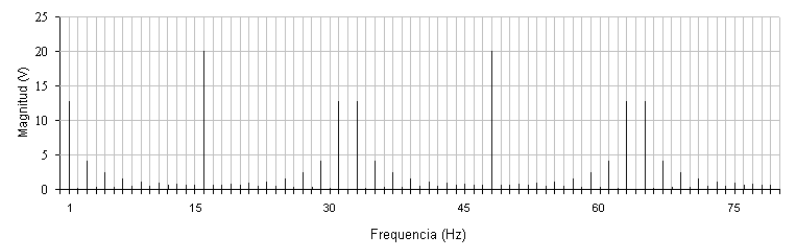

(b) $M_{f}=16 ; \quad I_{M}=0.7 ; \quad \phi=11.25^{\circ}$

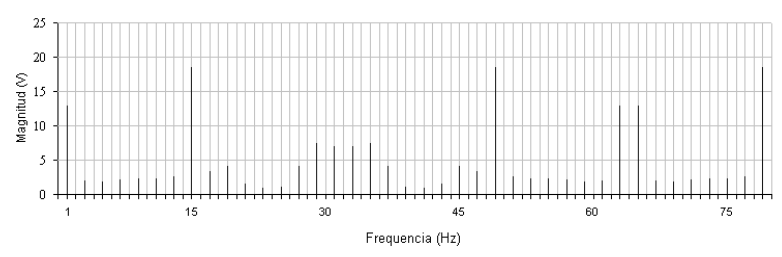

(c) $M_{f}=15 ; \quad I_{M}=0.7 ; \quad \phi=18^{\circ}$

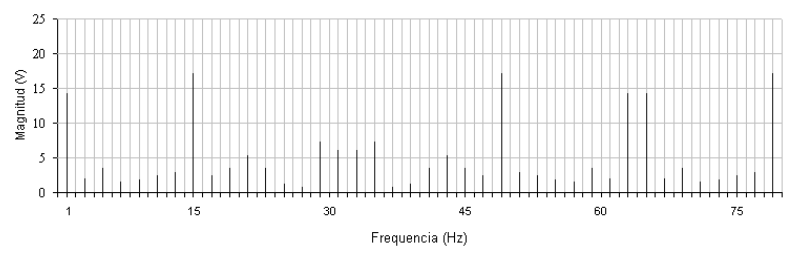

(d) $M_{f}=15 ; \quad I_{M}=0.7 ; \quad \phi=0^{\circ}$

Figure 6 Harmonics elimination 


\section{E. Intel $80 C 196$ microcontroller}

The 80C196MC microcontroller provide high efficiency in control applications where high speed is a priority.

A waveform generator simplifies the work in driving 3phase AC induction motors. The waveform generator can produce three independent pairs of complementary PWM outputs, which share a common carrier period, dead time, and operating mode. Once it is initialized, the waveform generator operates without CPU intervention unless you need to change a duty cycle [2].

The analog-to-digital (A/D) converter converts an analog input voltage to a digital equivalent. Resolution is either 8 or 10 bits; sample and convert times are programmable. The A/D scan mode of the PTS facilitates automated A/D conversions and result storage [2].

\section{INVERTER DESIGN}

\section{A. Power circuit inverter design}

The inverter power in the three-phase output is $2 \mathrm{hp}$.

Rectifier Bridge: DC voltage is generated by six pulse not controlled rectifier and is filtered by a capacitor. When powering up a preload capacitor to avoid damages to the rectifier bridge components.

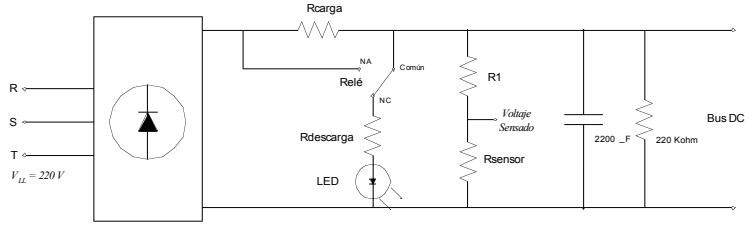

Figure 7 capacitor preload circuit

Inverter Bridge: The inverter three-phase bridge is formed by six IGBTs. The bridge includes IGBTs snubber protections.

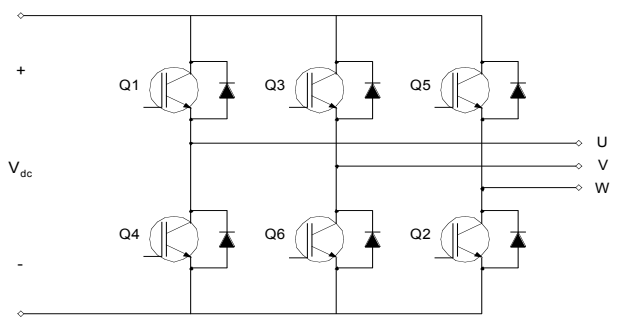

Figure 8 Inverter Bridge

\section{B. Control circuit}

The control circuit is the intelligent part of the system. It generates the control pulses, communicates with the user and protects the inverter of possible faults. The control circuit employs two microcontrollers.

Man-machine Interface: Human-Machine Interface (HMI) core is a microcontroller PIC16F876. The HMI is the user interface with the system. The HMI processes orders and peripheral signals, and it sends concrete instructions to the 80C196MC.
Motor Control: $80 \mathrm{C} 196 \mathrm{MC}$ microcontroller makes the task of the motor operation. It generates the control signals for the speed motor variation, acceleration ramps, torque compensation, and detection of faults.

The Waveform Generator (WG) performs the SPWM generation. The WG provides three independent pairs of PWM complemented outputs. These outputs share a same carrier, dead time and way of operation.

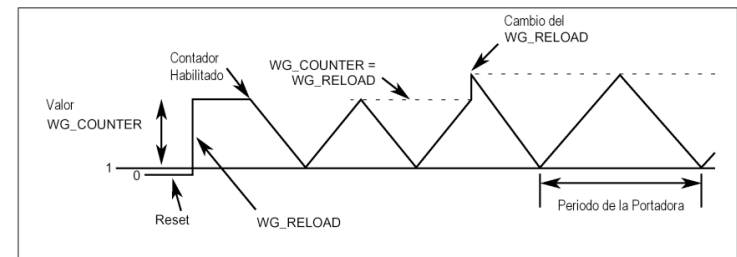

Figure 9 Triangular Generation [2]

The number of points that form the sine wave determines the MI, in this work the sine waveform has 105 points. It reduces the multiple of three harmonics and is sufficiently high to obtain high frequency switching harmonics.

If, the maximum peak of the sinusoidal waveform and the minimum peak of the triangular waveform are at the same place, the amplitude of certain harmonics are reduced. Figure 10 shows a sine wave formed by 15 points.

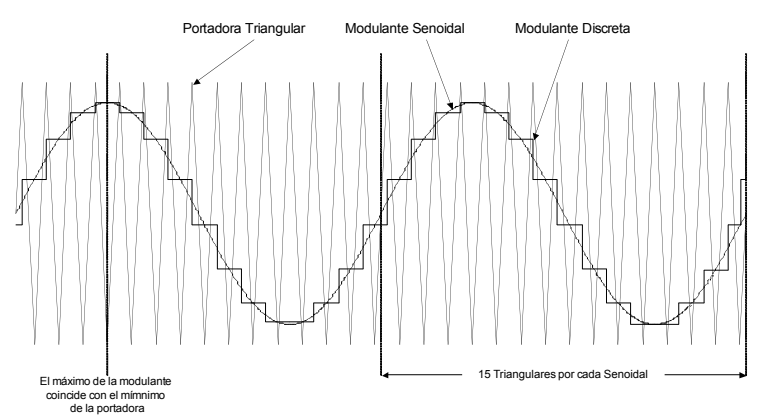

Figure 10 Sinusoidal generation

The MI is one at 52 Hertz. Thus, overmodulation is necessary.

\section{Torque compensation}

The amplitude torque reduces and losses increase at low speed. For this reason, a high torque at power up requires torque compensation. Compensation is implemented in the voltage. If terminal voltage increases then the maximum torque increases as well.

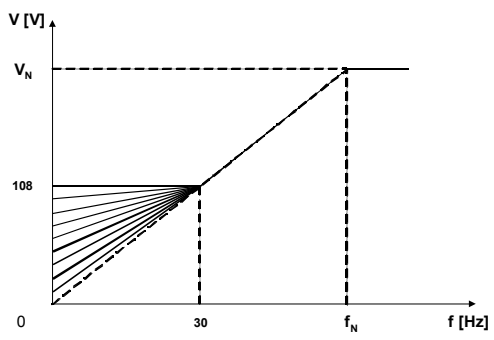

Figure 11 Torque Compensation 


\section{IGBTs driver}

The PCB driver for three-phase bridge generates the control signals with independent references from a single source. The recommended configuration is in Figure 12 [10].

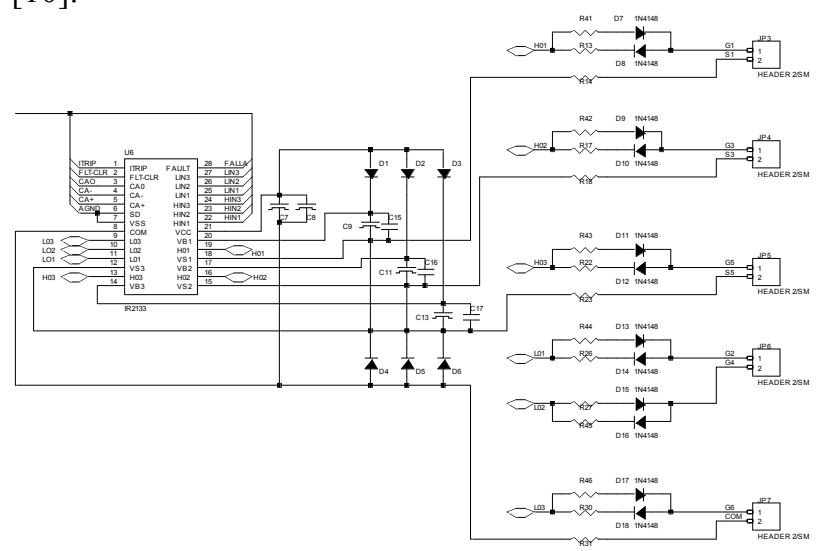

Figure 12 IGBT Driver

\section{EXPERIMENTAL RESULTS}

\section{A. Capacitor preload and unload}

The preload (Figure 13) is necessary to avoid damages in rectifier bridge diodes.

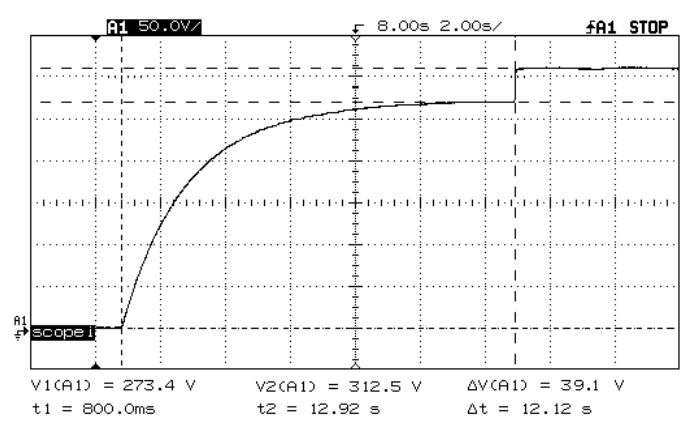

Figure 13 Capacitor Load

The unload (Figure 14) is necessary to avoid a dangerous voltage while the module is not operating.

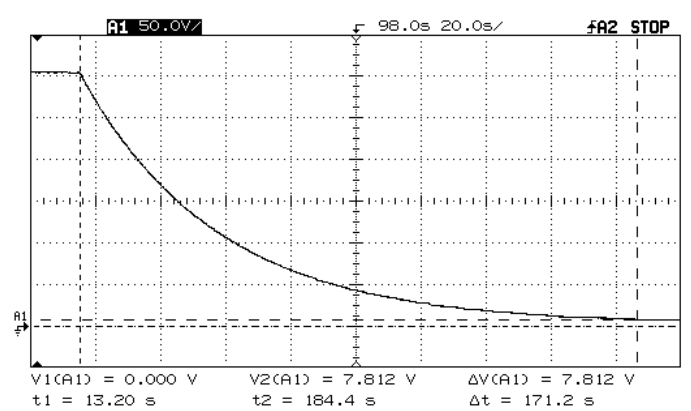

Figure 14 Capacitor discharge

\section{$B$. Inverter control and frequency variation}

Figure 15 presents the turn-on and turn-off characteristics of an IGBT in the inverter bridge.

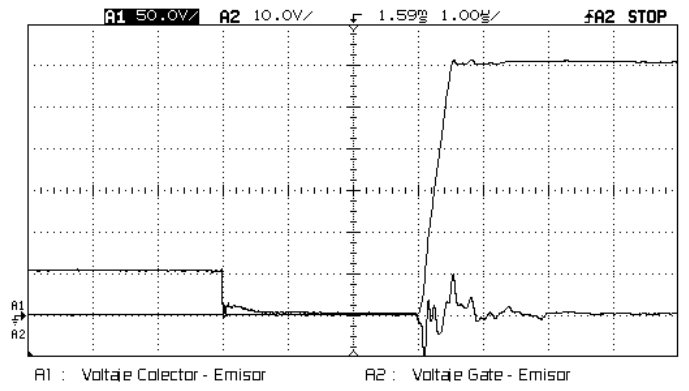

Figure 15 IGBT turn-on and turn-off

The motor voltage and current waveform are presented in Figure 16.
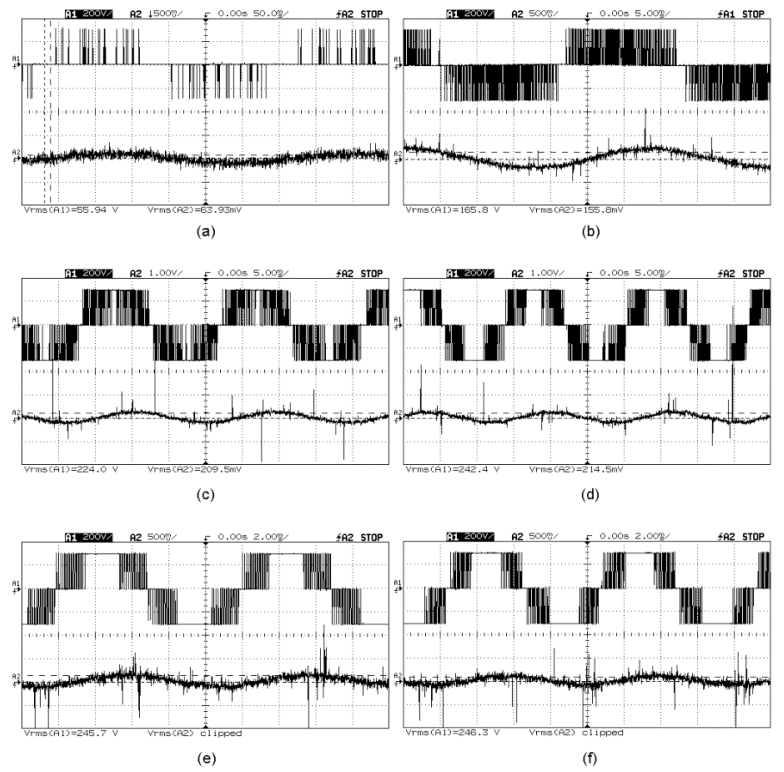

Figure 16 Motor voltage and current waveform

The relation between fundamental RMS voltage and DC bus voltage versus frequency is showed Figure 17.

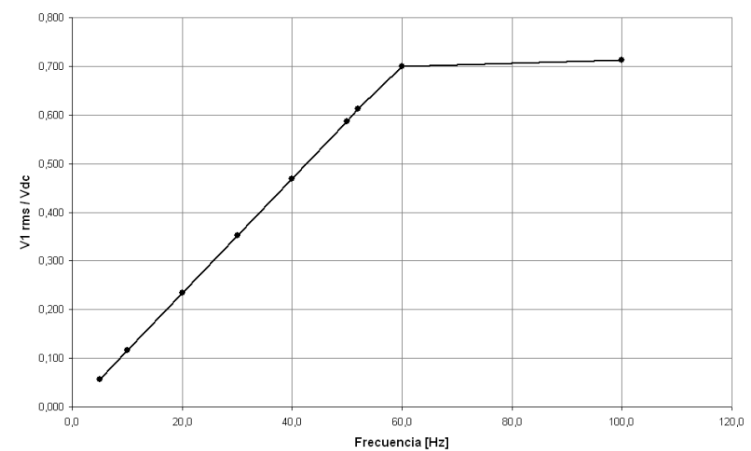

Figura $17 V_{L L 1 R M S} / V_{d c}$ vs. frequency 
The vector diagram (Figure 19) shows that voltage and current waveform are not in phase.
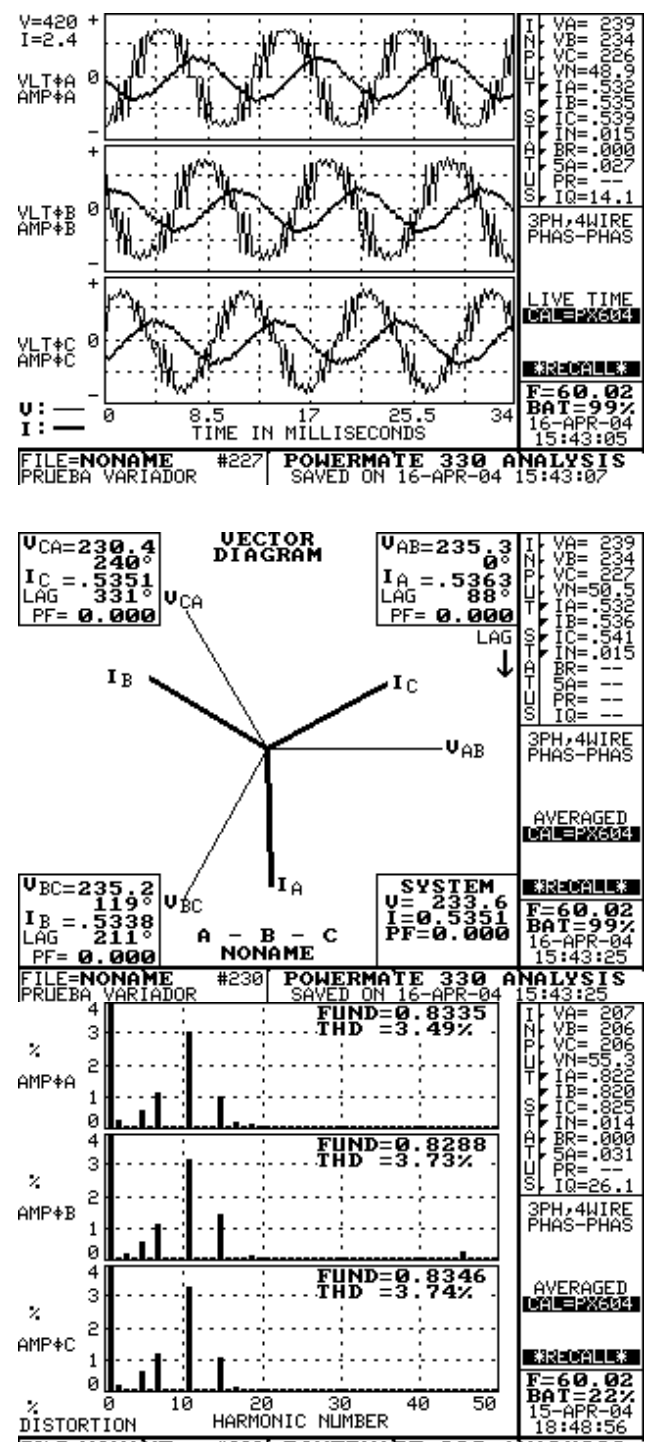

TISTENONATE
PREEBA YARTADOR

(a) $52[\mathrm{~Hz}]$

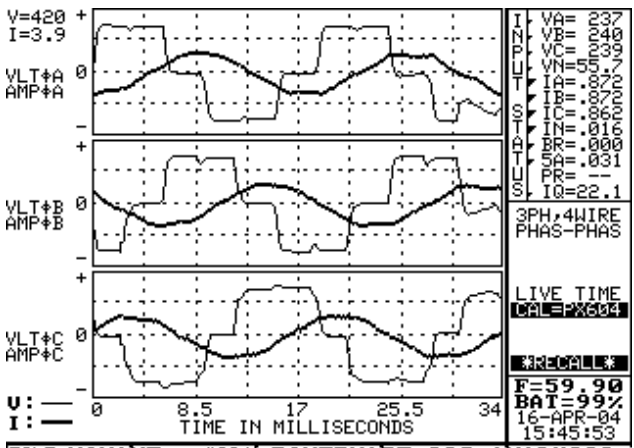

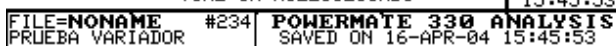

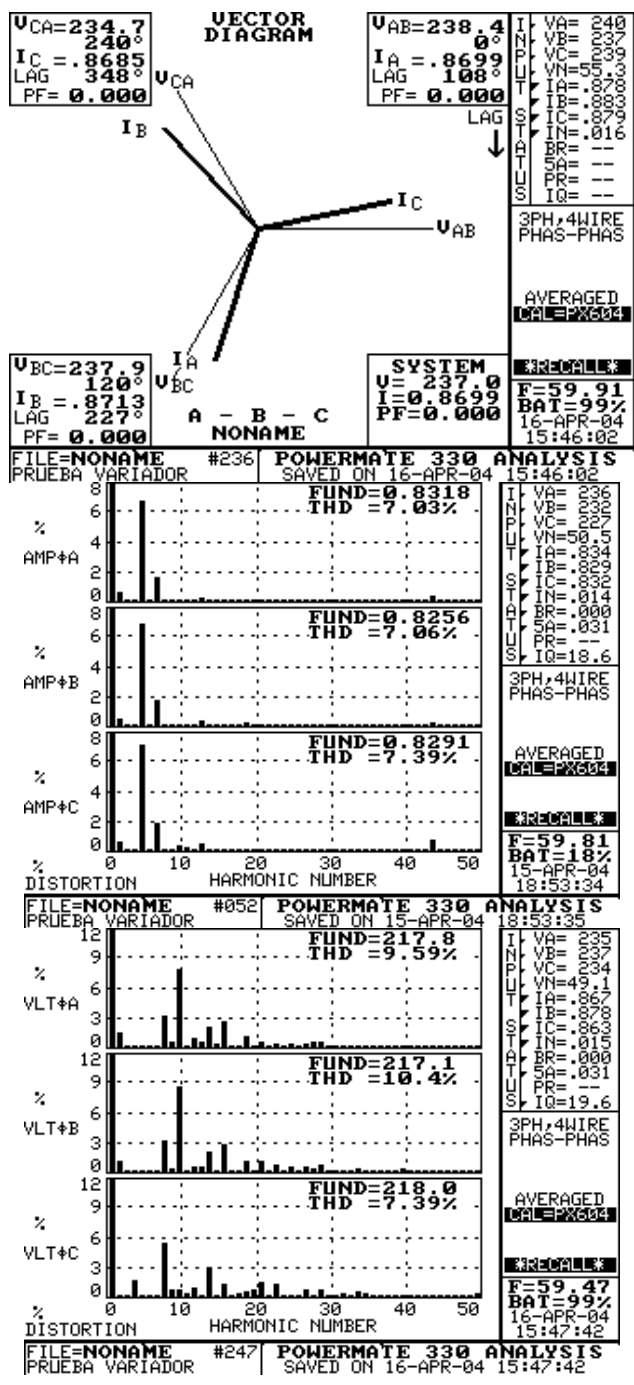

(b) $60[\mathrm{~Hz}]$

Figura 18 Vector diagram

\section{Acceleration and deceleration ramps}

An acceleration ramp avoids a high current at startup. This module implements three ramps: linear, $\mathrm{S}$ type to $50 \%$ and S type to the $100 \%$.

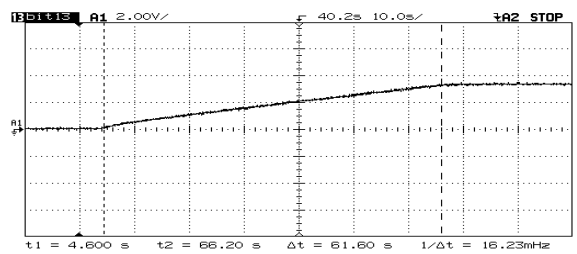

(a) Lineal ramp

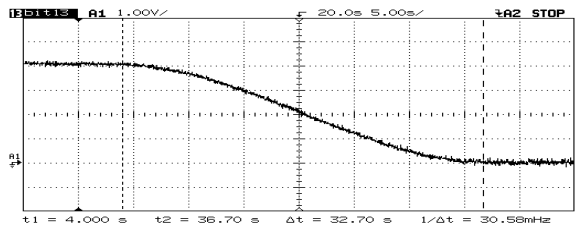

(b) $\mathrm{S} 100 \%$ ramp 


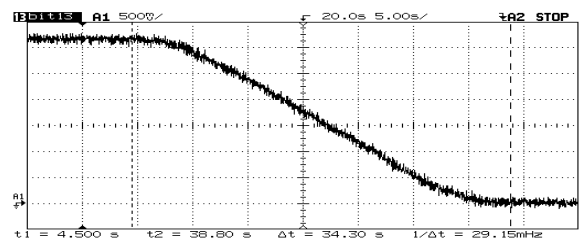

(b) S 50\% ramp

Figura 20 Ramps

\section{CONCLUSIONS}

Motor voltage and current waveform have a low harmonic content using SPWM technique.

The latch-up phenomenon (IGBT like thyristor) appears with high switching frequencies due to an increase in $\mathrm{dv} / \mathrm{dt}$ in the IGBTs. Thus, gate and emitter resistor are necessary to modify element characteristics and reduce disturbances in the IGBT commutation.

The development of an algorithm with constant MI reduces current distortion.

The general purpose microcontroller is not efficient in speed motor control. Thus, it is necessary to work with a specialized microcontroller.

\section{REFERENCES}

[1] MOHAN, Ned, UNDELAND Tore M., ROBBINS William P., POWER ELECTRONICS: Converters, Applications, and Design, John Wiley \&Sons, Inc, Republic of Singapore, 1989

[2] INTEL CORPORATION, 8XC196MC, 8XC196MD, 8XC196MH Microcontroller User's Manual, USA, October 1995.

[3] LAI, Jason, BOROJEVIC, Dusan, HUANG, Alex, Optimized Harmonic Stepped-Waveform for Multilevel Inverter, Siriroj Sirisukprasert, Blackburgs Virginia, 1999

[4] HAVA, Ahmet, SUL, Seung-Ki, Dynamic Overmodulation Characteristics of Triangle Intersection PWM Methods, IEEE Industry Applications Society, Annual Meeting Volume 2, New Orleans Louisiana, 1997

[5] POMILIO, J. A., Electrónica de Potencia, UNICAMP, Brasil, 2001

[6] RIVERA, Pablo, Control de Máquinas Eléctricas, EPN, 2000

[7] MICROCHIP TECHNOLOGY INCORPORATED, PIC16F87X Data Sheet, USA, 2001

[8] INTERNATIONAL RECTIFIER, IGBT Design Guide - Insulated Gate Bipolar Transistor, International Rectifier, California USA

[9] INTERNATIONAL RECTIFIER, Motor Drive Control IC - Designer's Manual, International Rectifier, California USA

[10] ZHANG, Yi, SOBHANI, Saed, CHOKHAWALA, Rahul, Snubber Considerations for IGBT Applications, International Rectifier Corporations, Technical Papers.

[11] NATIONAL SEMICONDUCTOR, Linear Applications Handbook, National Semiconductors, 1994. 